\title{
Anticoagulation for cardiopulmonary bypass: Is a replacement for heparin on the horizon?
}

Theodore E. Warkentin, MD

See related articles on pages 533 and 686.

From the Department of Pathology and Molecular Medicine, and the Department of Medicine, McMaster University, Hamilton, Ontario, Canada.

Dr Warkentin has a financial relationship with several of the manufacturers (GlaxoSmithKline, Medicines Co., and Organon) of anticoagulants discussed in this editorial. Received for publication Nov 1, 2005; accepted for publication Nov 1, 2005.

Address for reprints: Theodore E. Warkentin, MD, Hamilton Regional Laboratory Medicine Program, Hamilton Health Sciences (General Site), 237 Barton St E, Hamilton, Ontario L8L 2X2, Canada (E-mail: twarken@mcmaster.ca).

J Thorac Cardiovasc Surg 2006;131:515-6 $0022-5223 / \$ 32.00$

Copyright (๑) 2006 by The American Association for Thoracic Surgery

doi:10.1016/j.jtcvs.2005.11.012
$\mathrm{U}$ nfractionated heparin was first used in 1953 for cardiac surgery employing cardiopulmonary bypass $(\mathrm{CPB})^{1}$ and has remained the standard anticoagulant ever since. This near-monopoly status should not imply ideal drug properties. Indeed, heparin has several disadvantages: it poorly inhibits fibrin-bound thrombin, and thus thrombin is generated progressively during $\mathrm{CPB}$; its thrombin inhibition is only indirect (via antithrombin) and leads to antithrombin depletion, with potential for adverse consequences ${ }^{2}$; and its monitoring (by activated clotting time $[\mathrm{ACT}]$ ) only roughly estimates anticoagulant effect. Moreover, heparin's antidote, protamine, is itself problematic: its shorter half-life can lead to bleeding (via protamine "rebound") and its foreign structure can trigger life-threatening hypersensitivity reactions.

A largely unexplored issue is whether heparin's large size and strong negative charge, which result in binding to many proteins, are responsible for certain adverse events associated with CPB. Indeed, one protein to which heparin binds is a positively charged chemokine, platelet factor 4 (PF4). The resulting complexes of PF4 and heparin are very immunogenic: detectable antibodies against PF4/heparin complexes develop in as many as $70 \%$ of patients after heparin exposure during CPB. ${ }^{3}$ In $1 \%$ to $3 \%$ of patients, the levels of these antibodies are sufficiently great, and their platelet-activating properties sufficiently pathologic, that if the patient continues to receive heparin for a week or more after cardiac surgery, immune heparin-induced thrombocytopenia (HIT) results, with high risk for the development of venous or arterial thrombosis. ${ }^{4}$ In a few patients, HIT results even if postoperative heparin is not given, because of the autoimmune-like platelet-activating properties of these unusually pathologic HIT antibodies. ${ }^{5}$

A largely anecdotal experience has developed with alternative nonheparin anticoagulants for patients requiring CPB in whom heparin is considered absolutely or relatively contraindicated because of acute or previous HIT. These agents include the heparinoid, danaparoid, and the direct thrombin inhibitors, lepirudin and argatroban. ${ }^{4}$ The largest patient series involved danaparoid ${ }^{6}$ and lepirudin. ${ }^{7}$ Although many patients had satisfactory outcomes, problems such as excess bleeding and drug accumulation in the renally compromised patient have limited their use beyond HIT. None of these agents has been compared systematically with heparin for routine $\mathrm{CPB}$ anticoagulation.

At least, this was the situation until the arrival of bivalirudin. This "hirulog" (analog of hirudin) possesses a relatively short half-life (25-30 minutes) and exhibits predominant nonorgan metabolism via proteolysis. ${ }^{8}$ Thus, significant drug clearance occurs even despite dual renal and hepatic compromise. However, this feature also represents a potential limitation: new drug must be constantly infused to maintain anticoagulation, as stagnant bivalirudin-anticoagulated blood will eventually thrombose, with implications for clotting within the $\mathrm{CPB}$ circuit and reservoir and for 
managing blood cardioplegia. Thus, the perfusionist, cardiac anesthesiologist, and cardiac surgeon need to adapt their techniques and procedures to the properties of this agent. $^{8}$

Previously, bivalirudin compared favorably with heparin/protamine in a randomized trial for anticoagulation during "off-pump" cardiac surgery and was associated with a significantly lower rate of graft occlusion. ${ }^{9}$ In this issue of this Journal, Dyke and colleagues ${ }^{10}$ report the results of a $2: 1$ randomized trial comparing bivalirudin $(\mathrm{n}=98)$ versus heparin/protamine $(\mathrm{n}=52)$ for "on-pump" anticoagulation. The bivalirudin dosing schedule (bolus: $1 \mathrm{mg} / \mathrm{kg}$ [plus 50 $\mathrm{mg}$ in pump prime]; infusion: $2.5 \mathrm{mg} \cdot \mathrm{kg}^{-1} \cdot \mathrm{h}^{-1}$ [to maintain ACT $>2.5$ times baseline]) is approximately $30 \%$ greater than when used for off-pump surgery. The results suggest that bivalirudin could emerge as the first serious candidate to displace heparin from its half-century dominance in the cardiac operating suite.

In this small trial, no significant difference in the primary end point of procedural success (absence of death, non-Qwave myocardial infarction (MI), stroke, repeat coronary revascularization) was seen: bivalirudin, $94.8 \%$ vs heparin, $92.2 \%$ (12-week follow-up). There was greater early postoperative blood loss with bivalirudin (median at 2 hours, 238 vs $160 \mathrm{~mL} ; P=.0009$ ) and numerically higher rate of reoperation for bleeding (5.1\% vs $1.9 \% ; P=.67)$, but an offsetting tendency to less perioperative non-Q-wave MI (5.1\% vs $9.6 \% ; P=.32)$. Potentially, the greater ability of bivalirudin to inhibit fibrin-bound thrombin compared with heparin might be advantageous in reducing risk of $\mathrm{CPB}$ associated thrombosis.

What subsequent data could promote widespread adoption of bivalirudin anticoagulation for CPB? Larger studies that establish comparable safety of bivalirudin and that support at least one major clinically relevant advantage over heparin/protamine would likely be needed. Important such end points could include reduced postoperative MI or stroke, reduced bleeding, or, as suggested by the off-pump trial, ${ }^{9}$ improved long-term graft patency. From the perspective of the cardiac surgeon, anesthesiologist, and perfusionist, there must exist both the perception and reality that intraoperative bivalirudin dosing and monitoring can be safely and easily managed. Finally, an important "bivalirudin bonus" that could tip the balance toward widespread adoption for cardiac surgery might be avoidance of postoperative HIT (however, supportive data on formation of platelet-activating anti-PF4/ heparin antibodies were not provided in the current report). Maybe one day changing the way we administer anticoagulation during $\mathrm{CPB}$ will change the outcomes of cardiac surgery for the better.

\section{References}

1. Cohn LH. Fifty years of open-heart surgery. Circulation. 2003;107: 2168-70.

2. Ranucci M, Frigiola A, Menicanti L, Cazzaniga A, Soro G, Isgro G. Risk factors for fatal myocardial infarction after coronary bypass surgery. Eur J Anaesthesiol. 2001;18:322-9.

3. Warkentin TE, Sheppard JI. No significant improvement in diagnostic specificity of an anti-PF4/polyanion immunoassay with use of high heparin confirmatory procedure. J Thromb Haemost. 2006;4:281-2.

4. Warkentin TE, Greinacher A. Heparin-induced thrombocytopenia and cardiac surgery. Ann Thorac Surg. 2003;76:2121-31.

5. Warkentin TE, Kelton JG. Delayed-onset heparin-induced thrombocytopenia and thrombosis. Ann Intern Med. 2001;135:502-6.

6. Magnani HN, Beijering RJR, ten Cate JW, Chong BH. Orgaran anticoagulation for cardiopulmonary bypass in patients with heparininduced thrombocytopenia. In: Pifarré R, editor. New anticoagulants for the cardiovascular patient. Philadelphia: Hanley \& Belfus; 1997. p. $487-500$

7. Koster A, Hansen R, Kuppe H, Hetzer R, Crystal GJ, Mertzlufft F. Recombinant hirudin as an alternative for anticoagulation during cardiopulmonary bypass in patients with heparin-induced thrombocytopenia type II: a 1-year experience in 57 patients. J Cardiothorac Vasc Anesth. 2000;14:243-8.

8. Warkentin TE, Koster A. Bivalirudin: a review. Expert Opin Pharmacother. 2005;6:1349-71.

9. Merry AF, Raudkivi PJ, Middleton NG, McDougall JM, Nand P, Mills $\mathrm{BP}$, et al. Bivalirudin versus heparin and protamine in off-pump coronary artery bypass surgery. Ann Thorac Surg. 2004;77:925-31

10. Dyke CM, Smedira NG, Koster A, Aronson S, McCarthy HL II, Kirshner R, et al. A comparison of bivalirudin to heparin with protamine reversal in patients undergoing cardiac surgery with cardiopulmonary bypass: The EVOLUTION-ON study. J Thorac Cardiovasc Surg. 2006;131:533-9. 